\title{
The involvement of E6, p53, p16, MDM2 and Gal-3 in the clinical outcome of patients with cervical cancer
}

\author{
ANNIKA STIASNY $^{1 *}$, CHRISTOPH P. FREIER $^{1 *}$, CHRISTINA KUHN $^{1}$, SANDRA SCHULZE $^{1}$, \\ DORIS MAYR ${ }^{2}$, CHRISTOPH ALEXIOU ${ }^{3}$, CHRISTINA JANKO ${ }^{3}$, IRMI WIEST $^{1}$, \\ CHRISTIAN DANNECKER ${ }^{1}$, UDO JESCHKE ${ }^{1}$ and BERND P. KOST ${ }^{1}$
}

\begin{abstract}
Departments of ${ }^{1}$ Obstetrics and Gynecology and ${ }^{2}$ Pathology, Ludwig-Maximilians-University of Munich, D-80337 Munich;
${ }^{3}$ Department of Otorhinolaryngology, Head and Neck Surgery, Section of Experimental Oncology and Nanomedicine,

Else Kröner-Fresenius Foundation Professorship, University Hospital Erlangen, D-91054 Erlangen, Germany
\end{abstract}

Received December 7, 2016; Accepted February 3, 2017

DOI: $10.3892 / \mathrm{ol} .2017 .6752$

\begin{abstract}
High-risk human papilloma virus (HPV) is the leading cause of cervical cancer. HPV oncogenes are responsible for the development of malignancy, and the E6 oncoprotein that HPV expresses induces the degradation of tumour suppressor protein p53 (p53). This degradation leads to the upregulation of $\mathrm{p} 16$; however, unidentified proteins may also serve a role in the development and progression of cervical cancer. Therefore, the aim of the present study was to analyse the expression levels of E6, p53, p16, MDM2 proto-oncogene (MDM2) and galectin-3 (gal-3) in cervical cancer specimens. A total of 250 cervical cancer tissue slides were used. The expression of E6, p53, p16, MDM2 and gal-3 was analysed with immunohistochemical methods and a semi-quantitative scoring. SPSS software was used for the statistical evaluation of staining results and survival analysis of patients with cervical cancer. Cervical cancer specimens demonstrated significantly increased E6 staining with advanced T-status and increased International Federation of Gynecology and Obstetrics classification. E6, p53 and p16 demonstrated significantly different expression levels in squamous epithelial tissue compared with adenocarcinomas. MDM2 and gal-3 demonstrated positively correlated expression levels in cervical cancer. In addition, gal-3 expression was correlated with poor prognosis in p16-negative cases. A negative correlation between the expression of E6 and a mutated form of p53 was also identified in cervical cancer. p53 mutation was demonstrated to be common in cervical cancer, and gal-3 and MDM2 appeared to act in a combined
\end{abstract}

Correspondence to: Professor Udo Jeschke, Department of Obstetrics and Gynecology, Ludwig-Maximilians-University of Munich, 11 Maistrasse, D-80337 Munich, Germany

E-mail: udo.jeschke@med.uni-muenchen.de

${ }^{*}$ Contributed equally

Key words: cervical cancer, E6 oncoprotein, p53, p16, MDM2, galectin-3 manner in this type of tumour. As gal-3 is overexpressed in the cervical cancer tissue of patients with poor prognosis, the use of gal-3 inhibitors should be investigated in future studies.

\section{Introduction}

Cervical cancer is the fourth most frequent cancer in women globally with $\sim 530,000$ new cases in 2012, accounting for $7.5 \%$ of all female cancer-associated mortalities (1). A major cause of cervical cancer is persistent infection with high-risk human papillomavirus (HR-HPV) (1). HPV subtypes 16 and 18 cause $\sim 70 \%$ of all cases of HPV $(1,2)$. At present, $>170 \mathrm{HPV}$ types have been identified (3). Infection with 15 subtypes of HPV (16, 18, 31, 33, 35, 39, 45, 51, 52, 56, 58, 59, 68, 73 and 82) may lead to cancer, which is why these 15 types are known as carcinogenic or high-risk types (4). The genome of human papillomaviruses consists of $\sim 8,000$ base pairs and contains six early genes (E6, E7, E1, E2, E4 and E5) and two late genes (L1 and L2) (5). Upon replication of the viral gene E6, E6 oncoprotein is expressed, which alters the cell cycle (6). E6 oncoprotein and E6-associated protein (E6-AP) form a complex that binds to $\mathrm{p} 53$ and causes its proteolytic degradation (7).

The tumour suppressor protein p53 (p53) signalling pathways leads to cell cycle arrest or apoptosis in case of DNA damage (8). As E6 oncoprotein induces the degradation of p53, the function of this important cell cycle protein is disturbed following HPV infection (9). In addition, the cell cycle regulation protein p16 is expressed at high levels in HPV-infected epithelial cells, and thus acts as a marker for the diagnosis of HPV-associated carcinoma $(9,10)$. In non-carcinoma tissues p53 is regulated by MDM2 proto-oncogene (MDM2) through a negative feedback mechanism. MDM2 promotes the ubiquitination and proteasome-dependent degradation of p53 (11). There is also an association between MDM2, p53 polymorphism and the progression of cervical carcinoma (12).

A protein previously demonstrated to be associated with cervical cancer is galectin-3 (gal-3) (5). Galectins are defined as lectins with a galactose-binding ability and a characteristic amino-acid sequence (13). Galectin is a name proposed by Hirabayashi and Kasai (14) for a family of animal lectins. Galectins are typically soluble and metal-independent in 
their activity (15). They have similar features to cytoplasmic proteins, including no disulfide bridges, no sugar chains, no signal sequences and, in most cases, their $\mathrm{N}$-terminal amino acids are acetylated (16). It is possible to classify galectins into the following three types on the basis of their structural architecture: Proto, chimera and tandem-repeat types. Gal-3 is a chimera-type galectin (17).

Gal-3 may increase the invasiveness of cervical cancer by activating vascular endothelial growth factor receptor-3 (5). Therefore, the aim of the present study was to systematically analyse the expression and interactions of E6, p53, p16, MDM2 and gal-3 in cervical cancer specimens.

\section{Materials and methods}

Ethical approval. The present study was approved by the local Ethics Committee of the Ludwig-Maximilians-University of Munich (approval no. 259-16; Munich, Germany), and was performed in compliance with the guidelines of the Helsinki Declaration. Patient data were fully anonymised.

Specimens. Archived formalin-fixed paraffin-embedded (FFPE) sections from 250 cases of cervical cancer were used in the present study; it was possible to analyse 248 cases as there was no tumour tissue present on two sections (Table I). Cervical dysplasia [cervical intra-epithelial neoplasia (CIN) stage III] (18) and non-dysplastic cervical tissue (3 sections of each) was used for the E6 immunohistochemical staining, and breast cancer tissue was used for the mutated p53 immunohistochemistry. Specimens were obtained from the Department of Obstetrics and Gynecology of Ludwig-Maximilians-University of Munich, and were obtained from patients undergoing surgery there between 1993 and 2002. Follow-up data were received from the Munich Cancer Registry (Munich Tumour Centre, Munich, Germany).

Immunohistochemistry. The FFPE sections (3- $\mu$ m-thick) were dewaxed in xylol, endogenous peroxidase was inhibited with $3 \%$ methanol $/ \mathrm{H}_{2} \mathrm{O}_{2}$ and sections were rehydrated in a descending ethanol gradient. To stain for mutated $\mathrm{p} 53$, wild-type p53, E6, gal-3 and MDM2, the slides were pre-treated in citrate buffer $\left(100^{\circ} \mathrm{C}\right.$; pH 6.0) for antigen retrieval. Following this, non-specific binding of the primary antibodies was blocked, and incubation with the primary antibodies followed (Tables II and III). Incubation with the secondary antibodies and the following steps of the detection system and colour development are illustrated in Tables II and III. For p16 detection, the specimens were automatically stained using the Ventana BenchMark XT Stainer (Ventana Medical Systems, Inc., Oro Valley, AZ, USA) and the CINtec Histology kit (cat. no. 9517; Roche Applied Science, Mannheim, Germany) according to the manufacturer's instructions, while all other antibodies were stained for manually. For wild-type p53, the slides were washed in PBS/0.05\% Tween-20. All other slides were washed in PBS only. Finally, the slides were counterstained with hemalaun (Waldeck GmbH, Münster, Germany) for $2 \mathrm{~min}$ at room temperature, dehydrated in an ascending series of ethanol and stored.

Slides were examined with a Zeiss Axiophot light photomicroscope (Zeiss GmbH, Jena, Germany). Digital images
Table I. Clinical parameters of the patients included in the present study.

\begin{tabular}{lcr}
\hline Clinical parameter & No./total no. & $\%$ \\
\hline Age (years) & & \\
$\leq 50$ & $143 / 248$ & 58 \\
$>50$ & $105 / 248$ & 42 \\
No. of metastasis positive lymph nodes & & \\
0 & $149 / 248$ & 60 \\
$1-4$ & $97 / 248$ & 39 \\
NA & $2 / 248$ & 1 \\
Tumour size (cm) & & \\
$<2$ & $111 / 248$ & 45 \\
$2-4$ & $128 / 248$ & 52 \\
$>4$ & $9 / 248$ & 3 \\
Tumour grade & & \\
I & $20 / 248$ & 8 \\
II & $141 / 248$ & 57 \\
III & $78 / 248$ & 31 \\
NA & $9 / 248$ & 4 \\
Tumour subtype & & \\
Squamous & $199 / 248$ & 80 \\
Adenocarcinoma & $49 / 248$ & 20 \\
Progression (over 236 months) & & \\
None & $190 / 248$ & 77 \\
$\geq 1$ & $58 / 248$ & 23 \\
Survival (over 236 months) & & \\
Right censured & $210 / 248$ & 85 \\
Succumbed & $38 / 248$ & 15 \\
\hline
\end{tabular}

NA, not applicable as data not available.

were obtained with a digital-camera system (CF20DXC; KAPPA Messtechnik, Gleichen, Germany). All specimens were evaluated by a pathologist. The intensity and distribution patterns of the staining reaction was evaluated by two blinded, independent observers, including the gynecological pathologist, using the semi-quantitative immunoreactive (IRS)-score, as previously described (19), to asses steroid receptors (20) and cathepsin D (21) expression. The IRS score was calculated by multiplication of optical staining intensity (graded as 0 , no staining; 1 , weak staining; 2 , moderate staining; and 3 , strong staining) and the percentage of positive stained cells ( 0 , no staining; $1, \leq 10 \%$ of the cells, $2,11-50 \%$ of the cells, $3=51-80 \%$ of the cells and $4, \geq 81 \%$ of the cells) and without knowing the pathological evaluation, the diagnosis or the standard performed hematoxylin reaction for $2 \mathrm{~min}$ at room temperature for each specimen.

Statistical analysis. Data were analysed using SPSS software (version 19.0; IBM SPSS, Armonk, NY, USA) for Microsoft Windows and visualised using Microsoft Office 7 (Microsoft Corporation, Redmond, WA, USA). Spearman coefficients were calculated to assess correlations, while the 
Table II. Procedures for gal-3 and MDM2 staining.

\begin{tabular}{|c|c|c|}
\hline Protocol & Gal-3 & MDM2 \\
\hline Blocking method & Horse serum ${ }^{\mathrm{a}}, 20 \mathrm{~min}, \mathrm{RT}$ & Goat serum ${ }^{\mathrm{a}}, 20 \mathrm{~min}, \mathrm{RT}$ \\
\hline $\begin{array}{l}\text { Primary antibody, dilution, } \\
\text { incubation duration, incubation } \\
\text { temperature, cat. no. }\end{array}$ & $\begin{array}{l}\text { Anti-galectin-3, } 1: 1,000 \text { in PBS, } \\
16 \mathrm{~h}, 4^{\circ} \mathrm{C} ; \mathrm{NCL}-\mathrm{GAL} 3^{\mathrm{b}}\end{array}$ & $\begin{array}{l}\text { Anti-MDM2, } 1: 100 \text { in PBS, } 16 \mathrm{~h} \text {, } \\
4^{\circ} \mathrm{C}, \mathrm{NCL}-\mathrm{MDM} 2^{\mathrm{b}}\end{array}$ \\
\hline $\begin{array}{l}\text { Secondary antibody, } \\
\text { dilution, incubation duration, } \\
\text { incubation temperature, cat. no. }\end{array}$ & $\begin{array}{l}\text { Biotynilated anti-mouse } \mathrm{IgG}^{\mathrm{a}} \text {, } \\
30 \text { min, RT; PK-6100 }\end{array}$ & $\begin{array}{l}\text { Biotinylated goat anti-mouse IgM, } \\
30 \text { min, RT ZMB2020 }\end{array}$ \\
\hline Detection of secondary antibody & ABC-complex ${ }^{\mathrm{a}}, 30 \mathrm{~min}$ & ABC-complex ${ }^{\mathrm{a}}, 30 \mathrm{~min}$ \\
\hline Chromogen & $1 \mathrm{mg} / \mathrm{ml} \mathrm{DAB}{ }^{\mathrm{d}}, 5 \mathrm{~min}$ & $1 \mathrm{mg} / \mathrm{ml} \mathrm{DAB}^{\mathrm{d}}, 1 \mathrm{~min}$ \\
\hline
\end{tabular}

${ }^{a}$ Vectastain ABC kit; Vector Laboratories, Inc., Burlingame, CA, USA. '№vocastra; Leica Microsystems GmbH, Wetzlar, Germany. 'Linaris GmbH, Dossenheim, Germany. ${ }^{\mathrm{d} D a k o}$, Glostrup, Denmark. Gal-3, galectin-3; MDM2, MDM2 proto-oncogene; Ig, immunoglobulin; $\mathrm{DAB}, 3,3$ '-diaminobenzidine; $\mathrm{RT}$, room temperature.

Table III. Procedures for mutated p53, wild-type p53 and E6 staining.

\begin{tabular}{|c|c|c|c|}
\hline Protocol & Mutated p53 & p53 wild-type & E6 \\
\hline Blocking method & Reagent $1^{\text {a }} ; 5$ min, RT & Reagent $1^{\mathrm{a}} ; 5 \mathrm{~min}, \mathrm{RT}$ & Reagent $1^{\text {a }} ; 5$ min, RT \\
\hline $\begin{array}{l}\text { Primary antibody, dilution, } \\
\text { incubation duration, incubation } \\
\text { temperature, cat. no. }\end{array}$ & $\begin{array}{l}\text { Anti-p53, } 1: 100 \text { in PBS, } \\
16 \mathrm{~h}, 4^{\circ} \mathrm{C}, \mathrm{ab} 32049^{\mathrm{b}}\end{array}$ & $\begin{array}{l}\text { Anti-p53, 1:200 in PBS, } \\
16 \mathrm{~h}, 4^{\circ} \mathrm{C}, \mathrm{ab} 26^{\mathrm{b}}\end{array}$ & $\begin{array}{l}\text { Anti-E6, } 1: 150 \text { in PBS, } \\
1 \mathrm{~h}, \mathrm{RT}, \mathrm{ab} 70^{\mathrm{b}}\end{array}$ \\
\hline Post blocking method & Reagent $2^{\mathrm{a}} ; 20 \mathrm{~min}, \mathrm{RT}$ & Reagent $2^{\mathrm{a}} ; 20 \mathrm{~min}, \mathrm{RT}$ & Reagent $2^{\mathrm{a}} ; 20 \mathrm{~min}, \mathrm{RT}$ \\
\hline $\begin{array}{l}\text { Secondary antibody, dilution, } \\
\text { incubation duration, incubation } \\
\text { temperature, cat. no. }\end{array}$ & $\begin{array}{l}\text { HRP-Polymer Reagent } 3^{\text {a }} \text {, } \\
30 \text { min, RT POLHRP-100 }\end{array}$ & $\begin{array}{l}\text { HRP-Polymer Reagent } 3^{\mathrm{a}} \text {, } \\
30 \text { min, RT POLHRP-100 }\end{array}$ & $\begin{array}{l}\text { HRP-Polymer Reagent } 3^{\text {a }} \text {; } \\
30 \text { min, RT POLHRP-100 }\end{array}$ \\
\hline Chromogen & $1 \mathrm{mg} / \mathrm{ml} \mathrm{DAB}^{\mathrm{c}}, 1 \mathrm{~min}$ & $1 \mathrm{mg} / \mathrm{ml} \mathrm{DAB}^{\mathrm{c}}, 1 \mathrm{~min}$ & $1 \mathrm{mg} / \mathrm{ml} \mathrm{DAB}^{\mathrm{c}}, 1 \mathrm{~min}$ \\
\hline
\end{tabular}

${ }^{\mathrm{a}}$ From the ZytoChem-Plus HRP Polymer-kit; Zytomed Systems GmbH, Berlin, Germany. ${ }^{\mathrm{b}} \mathrm{Abcam}$, Cambridge, UK. ${ }^{\mathrm{c}}$ Dako, Glostrup, Denmark. RT, room temperature; HRP, horseradish peroxidase; DAB, 3,3'-diaminobenzidine.

Mann-Whitney U test was applied to examine differences between groups. Differences in survival were assessed using the log-rank test and survival curves were plotted in accordance with Kaplan-Meier estimator. $\mathrm{P}<0.05$ was considered to indicate a statistically significant difference and data were expressed as the mean \pm standard error. Cox regression analysis was used to compare the risk of mortality in patients with and without gal-3 expression when the effects of further factors were accounted for. Independent variables included in the Cox regression model were gal-3 expression, age at the time of surgery, histological subtype, tumour size, lymph node status ( $\mathrm{pN}$ ), metastasis, tumour grade, International Federation of Gynecology and Obstetrics (FIGO) stage $(22,23)$, and E6, mutated p53 and MDM2 expression status.

\section{Results}

Evaluation of E6 oncoprotein immunohistochemistry and the detection of mutated p53 on control slides. CIN III tissue slides were used for the evaluation of E6 oncoprotein staining. Moderate expression levels of E6 were observed in the CIN III sections (Fig. 1A). There was no expression of the E6 oncoprotein, and therefore no staining observed, in the non-dysplastic cervical tissue (Fig. 1B). Breast cancer tissue was used to evaluate the staining of mutated p53 (Fig. 1C), which exhibited nuclear and cytoplasmic staining.

E6 oncoprotein staining. A total of $81 \%$ of all cervical cancer tissue examined expressed E6 oncoprotein (data not shown). Cervical cancer specimens demonstrated significantly increased staining with a higher $\mathrm{T}$ stage (according to the Tumor-Node-Metastasis classification system) (24). T1 stage carcinomas (Fig. 2A) demonstrated E6 staining with a median IRS of 2, while T2 (Fig. 2B) and T3 (Fig. 2C) stage carcinoma tissues had a significantly higher median E6 expression of IRS 3 ( $\mathrm{P}=0.017$; Fig. 2D).

FIGO 1 carcinoma tissues had a median E6 expression of IRS 2 (Fig. 2E). FIGO 2 (Fig. 2F) and FIGO 3 (Fig. 2G) carcinoma tissues had a median IRS of 4. FIGO 4-classified cervical cancer tissue had a median E6 IRS score of 6 (Fig. 2H). E6 demonstrated a significant positive correlation with the FIGO classification $(\mathrm{R}=0.277, \mathrm{P}<0.001$; Fig. 2I). 
$\mathbf{A}$

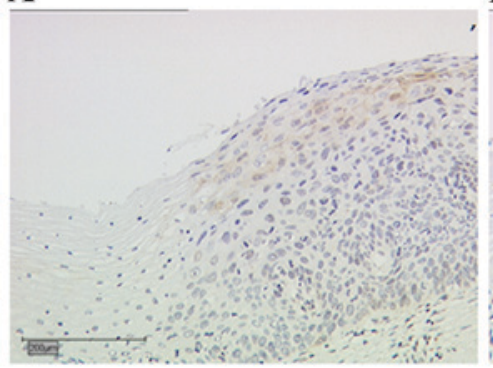

B

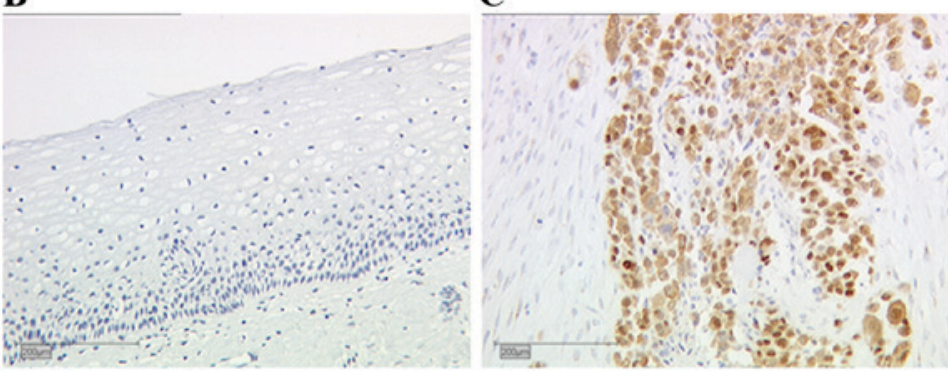

Figure 1. Representative images of the staining for E6 in dysplastic and non-dysplastic cervical tissue samples, and mutated tumour protein p53 in breast cancer samples. (A) E6 staining in cervical dysplasia. (B) No expression of E6 was detected in non-dysplastic cervix samples. (C) Breast cancer tissue demonstrated expression of mutated p53. Scale bar, $200 \mu \mathrm{m}$.
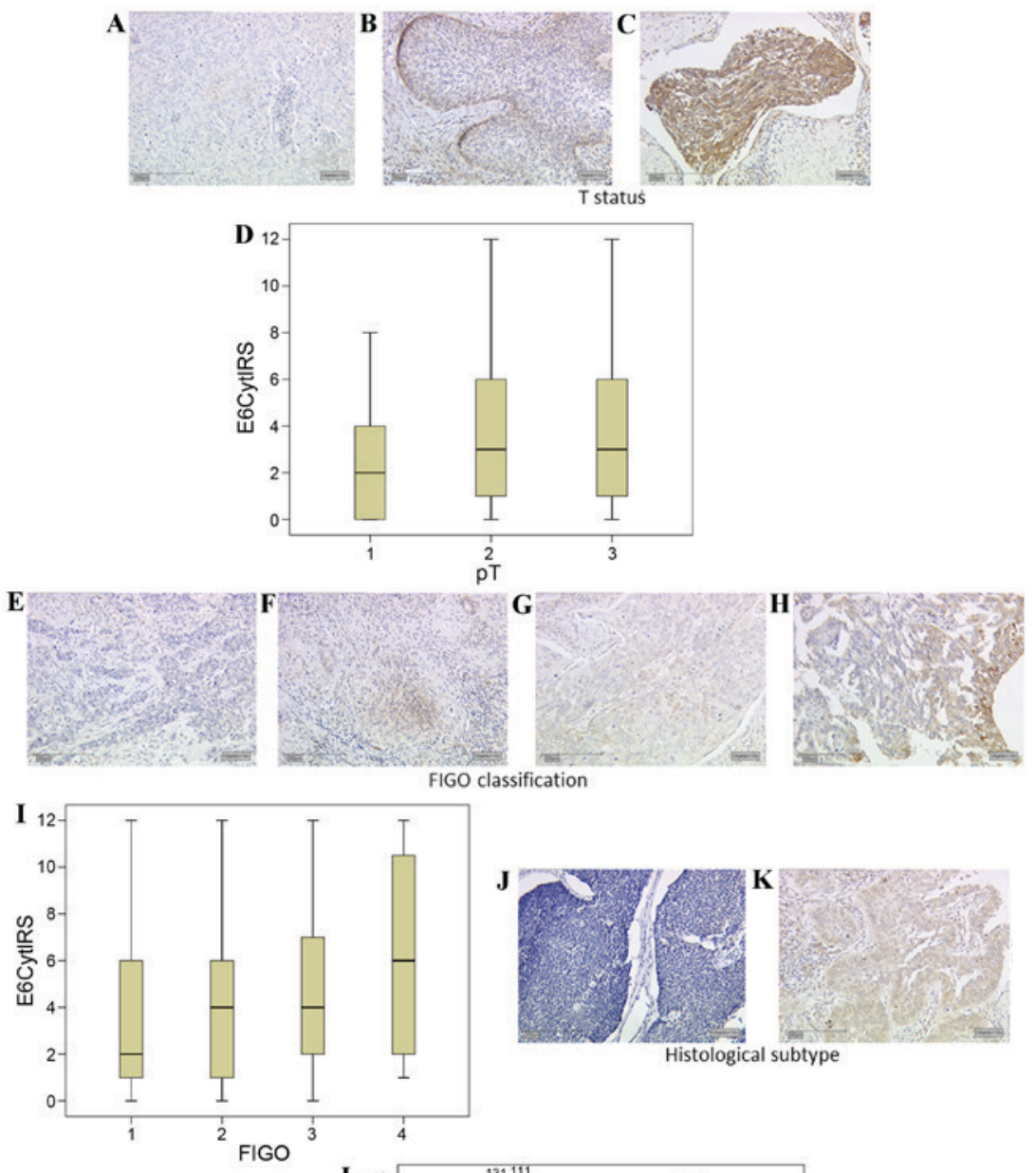

FIGO classification
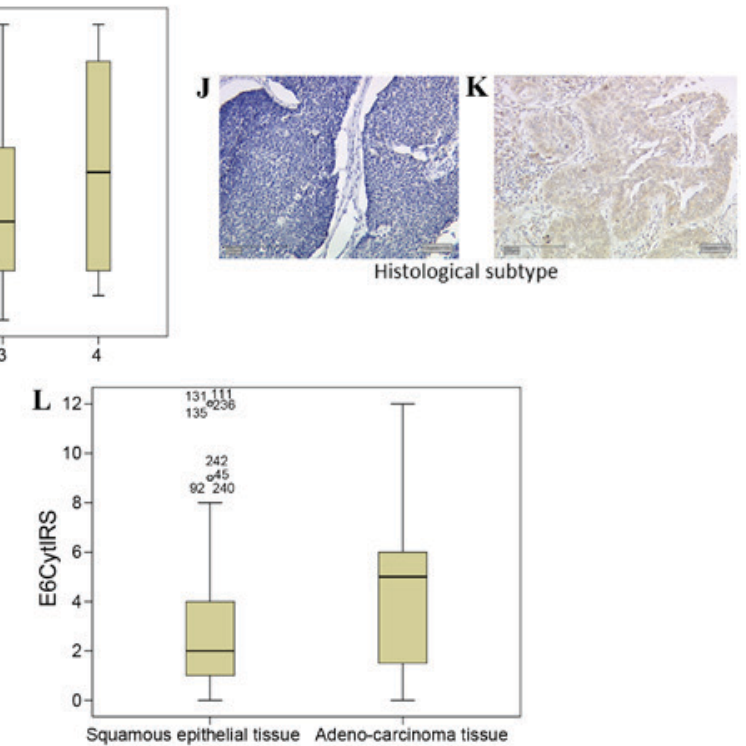

Histological subtype

Figure 2. E6 expression is enhanced with cervical cancer tumour staging. (A) Low intensity E6 expression was observed in T1 tumours, whereas (B) T2 and (C) T3 staged tumours demonstrated increased expression of E6. (D) Box plot summary of the IRS for each tumour stage ( $\mathrm{P}=0.017$, FIGO 1 vs. 3). E6 expression was positively correlated with FIGO classification, with (E) FIGO 1 classified tissue demonstrating low expression of E6 while (F) FIGO 2 and (G) FIGO 3 classified tissue demonstrated increased expression levels, and (H) FIGO 4 tissue further increased expression levels. (I) Box plot summary of the IRS for each FIGO stage (P<0.001, FIGO 1 vs. 4). (J) Squamous epithelial tissue demonstrated lower levels of E6 staining than (K) adenocarcinoma tissue. (L) Box plot summary of the IRS for each histological subtype. Scale bar, $200 \mu \mathrm{m}$. FIGO, International Federation of Gynecology and Obstetrics; IRS, immunoreactive score; E6Cyt, E6 cytoplasmic; pT, pathological tumour stage. 
A

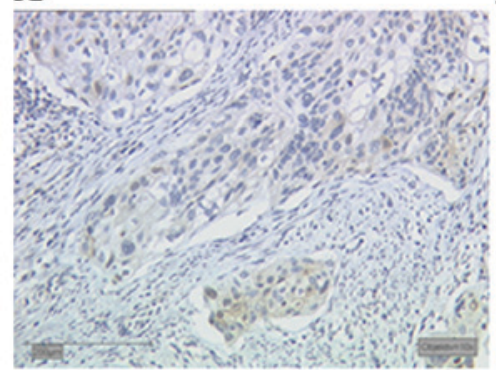

D

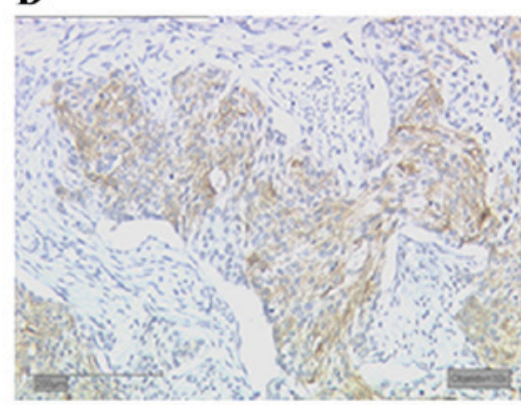

B

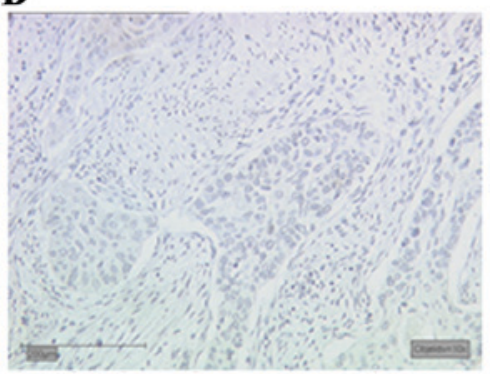

E

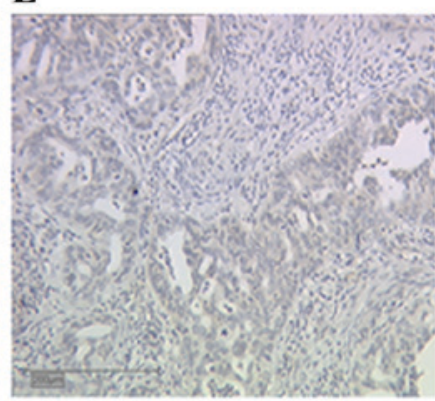

C

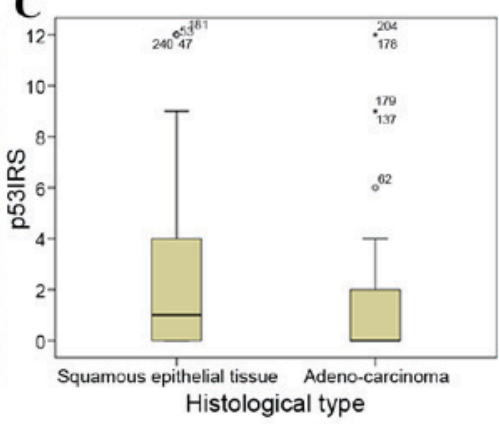

F

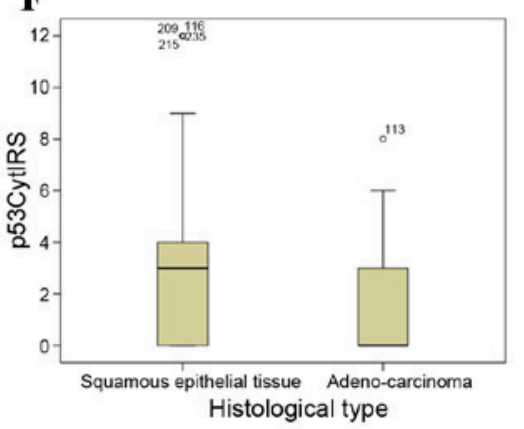

I

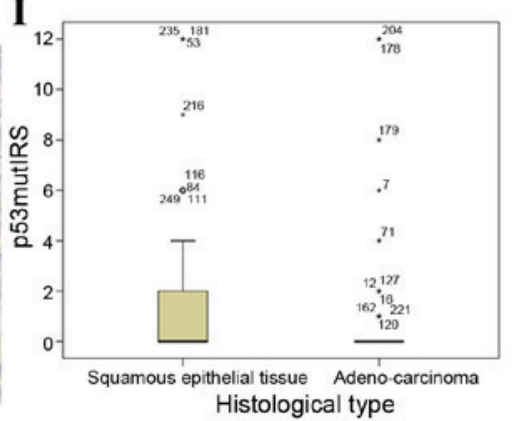

Figure 3. Tumour protein p53 expression in cervical cancer tissues. (A) Squamous epithelial tissue demonstrated a nuclear expression of wild-type p53, whereas (B) adenocarcinoma tissue had lower levels of p53 nuclear staining. (C) Box plot summary of the nuclear p53 IRS for each histological subtype. (D) Squamous epithelial tissue demonstrated higher expression of wild-type p53 in the cytoplasm compared with (E) adenocarcinoma tissue. (F) Box plot of the cytoplasmic p53 IRS for each histological subtype. (G) Squamous epithelial tissue demonstrated expression of mutated p53, while (H) adenocarcinoma tissue demonstrated almost no staining. (I) Box plot summary of the mutated p53 IRS for each histological subtype. Scale bar, $200 \mu \mathrm{m}$. IRS, immunoreactive score; p53Cyt, cytoplasmic wild-type p53; p53mut, mutant p53.

E6 demonstrated significantly different expression levels in cervical cancer tissue dependent on the histological subtype. Squamous epithelial carcinomas (Fig. 2J) had a median expression of IRS 2. Adenocarcinoma tissue (Fig. 2K) had significantly increased staining with a median of IRS 5 ( $\mathrm{P}=0.015$ vs. squamous epithelial carcinoma; Fig. 2L).

Wild-type and mutated p53 expression. Expression of wild-type p53 was observed in the nucleus and cytoplasm of 60 and $66 \%$ of all cervical cancer specimens, respectively. Significantly different expression levels in cervical cancer tissue in different histological subtypes were also observed for p53 expression. Wild-type p53 demonstrated a median nuclear expression (Fig. 3A) of IRS 1 in squamous epithelial tissue, whereas in adenocarcinoma tissue (Fig. 3B) the median nuclear expression was significantly decreased in comparison (IRS 0, P=0.024; Fig. 3C).

In addition to nuclear expression, wild-type cytosolic p53 expression also demonstrated significant differences associated with the histological subtype. In squamous epithelial tissue (Fig. 3D) a median expression of IRS 3 was observed, whereas in comparison the median cytosolic expression of p53 was significantly decreased in adenocarcinoma tissue (Fig. 3E) to IRS $0(\mathrm{P}<0.001$; Fig. $3 \mathrm{~F})$.

The monoclonal antibody that recognises a previously described mutated form of p53, (25) also revealed significant staining differences associated with the histological subtype of cervical cancer. In addition, $42 \%$ of all cervical cancer tissue slides demonstrated nuclear expression of mutated p53, and $67 \%$ of all cases demonstrated mutated p53 expression in the cytoplasm. Although the median expression of mutated p53 in squamous epithelial tissue (Fig. 3G) and adenocarcinoma tissue (Fig. 3H) was 0 , differences between the subtypes were significant $(\mathrm{P}=0.011$; Fig. 3I).

Expression of p16 oncoprotein in cervical cancer tissue. p16 overexpression is routinely used in the Pathology Department of the Ludwig-Maximilians-University of Munich as a marker for HPV-associated head and neck squamous carcinoma (11). A total of $94 \%$ of cervical carcinoma cases tested 
A
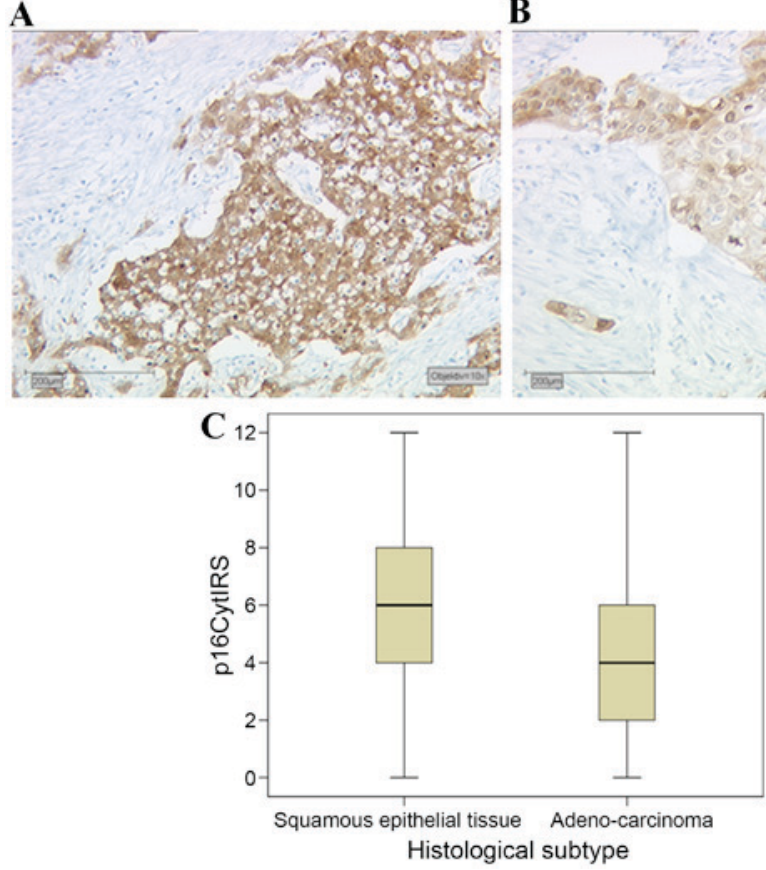

B

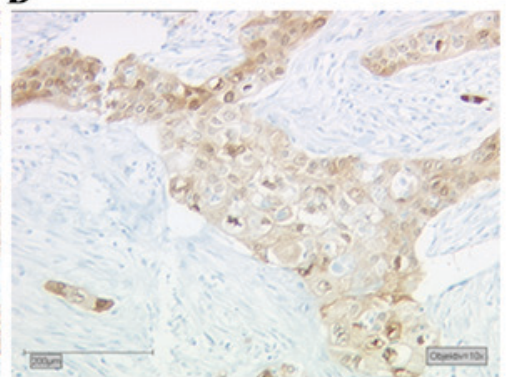

Histological subtype

Figure 4. Expression of p16 in cervical cancer tissues (A) Squamous epithelial tissue demonstrated higher p16 expression levels compared with (B) adenocarcinoma tissue. (C) Box plot summary of the p16 IRS for each histological subtype. Scale bar, $200 \mu \mathrm{m}$. IRS, immunoreactive score; p16Cyt, cytoplasmic p16.

A

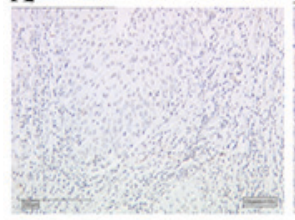

E

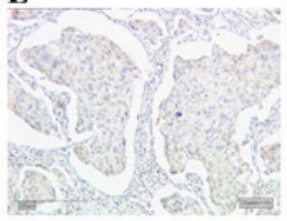

B

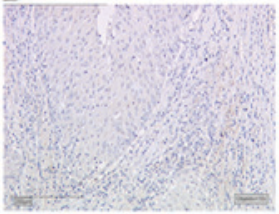

F

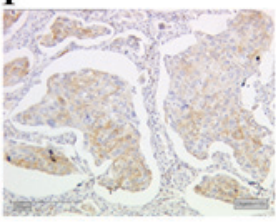

C

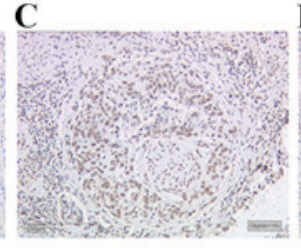

G

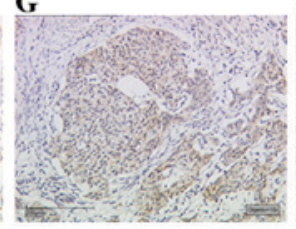

D

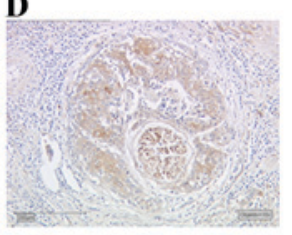

H

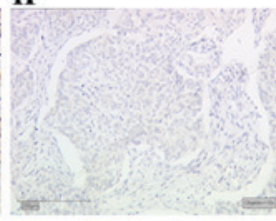

Figure 5. Expression of MDM2 and gal-3 in cervical cancer. Low expression of (A) MDM2 and (B) gal-3 was identified in the same area of cervical cancer. In another case, high expression of (C) MDM2 and (D) gal-3 were observed in the same are. Samples with (E) low E6 expression demonstrated high expression levels of (F) mutated p53. Another serial slide series with high expression of (G) E6 demonstrated low expression of (H) mutated p53. Scale bar, 200 $\mu \mathrm{m}$. MDM2, MDM2 proto-oncogene; gal-3, galectin-3.

demonstrated p16 expression, and $61 \%$ of these cases were p16-overexpressing according to pathological evaluation. The cell cycle protein p16 demonstrated significant differences in expression between different histological subtypes of cervical cancer. Squamous epithelial tissue (Fig. 4A) had a median expression of IRS 6, while adenocarcinoma tissue (Fig. 4B) had a significantly lower expression in comparison, with an IRS of 4 ( $\mathrm{P}<0.001$; Fig. 4C). Notably, p16 demonstrated no significant correlation with E6 oncoprotein expression (data not shown).

Correlation analysis. A significant correlation was identified between MDM2 and gal-3 expression in cervical cancer tissue ( $\mathrm{R}=0.181, \mathrm{P}=0.005$; data not shown). Cases of cervical cancer with low MDM2 expression (Fig. 5A) also demonstrated low gal-3 expression (Fig. 5B). Likewise, a case with high MDM2 expression (Fig. 5C) demonstrated high gal-3 expression (Fig. 5D). Cases of cervical cancer with low E6 oncoprotein expression (Fig. 5E) demonstrated enhanced staining of the mutated form of p53 in the same area of the tumour (Fig. 5F). However, cases with high expression of E6 (Fig. 5G) revealed low expression of mutated p53 (Fig. 5H). The statistical evaluation confirmed these results of serial section staining ( $\mathrm{R}=-0.140, \mathrm{P}=0.028$; Table IV). A significant correlation was also identified between the expression of MDM2 and mutated p53 in cervical cancer tissue $(\mathrm{R}=0.144, \mathrm{P}=0.025$; Table IV). The correlation analyses and clinical parameters are summarised in Table IV.

Gal-3 is a negative prognosticator in p16-negative patients with cervical cancer. In patients with cervical cancer with no or very low p16 expression, gal-3 expression was correlated with a 


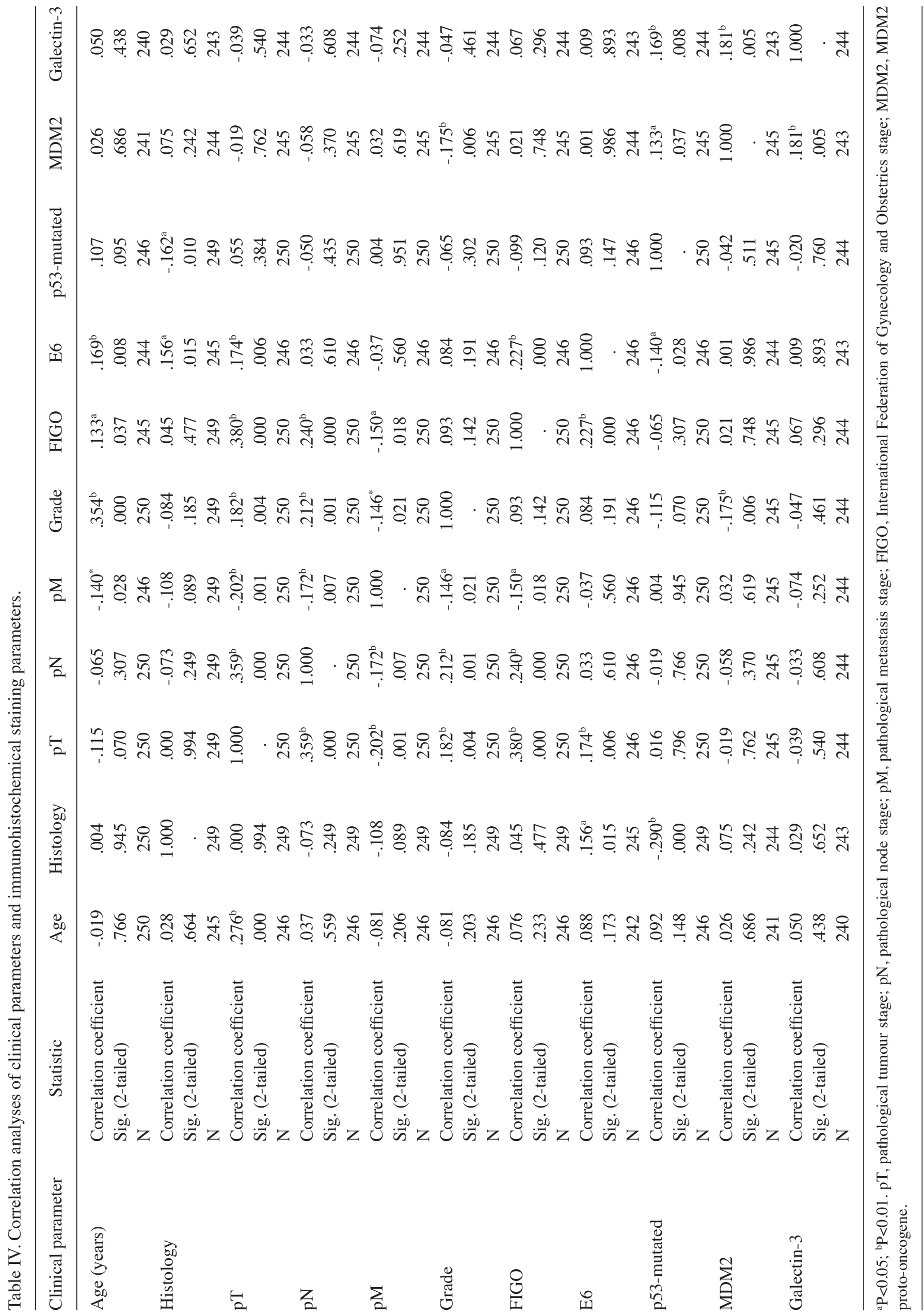




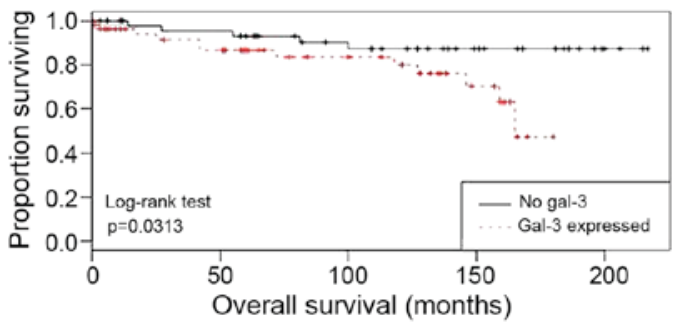

Figure 6. Kaplan-Meier overall survival analyses for patients with cervical cancer with gal-3 expression (red) compared with those with no gal-3 expression (black). Gal-3, galectin-3.

poor prognosis in overall survival analyses ( $\mathrm{P}=0.0313$; Fig. 6$)$. Multivariate Cox regression analysis was performed to test which histopathological variables were independent prognosticators for survival rate in the tested breast cancer collective. It was demonstrated that the histological subtype $(\mathrm{P}=0.02)$, tumour size $(\mathrm{P}=0.011)$ and $\mathrm{pN}(\mathrm{P}=0.045)$ were independent prognosticators for overall survival (Table $\mathrm{V})$. No significant effect was demonstrated for the other histopathological variables.

\section{Discussion}

Within the present study, immunohistochemical evaluation of E6 oncoprotein expression was conducted. In addition, E6 expression levels were demonstrated to be associated with the histological subtype. The expression of wild-type p53 and a mutated form of $\mathrm{p} 53$ were identified in the cervical cancer specimens tested. Finally, correlation analyses revealed a combined positive expression pattern for galectin-3 and MDM2, and a negative correlation between E6 and mutated p53 expression.

Although the early era of HPV research identified that $\leq 99.5 \%$ of cervical cancer cases are HPV-associated (26), it remains controversial in the literature whether viral load and disease severity are positively correlated (12). Therefore, the present study investigated a number of markers that are associated with HPV-driven changes in cell cycle proteins. Using these markers permitted a comparative analysis of the influence of HPV on the progression of cervical cancer for $>10$ years following surgery.

The replication of the viral genes E6 and E7 results in the cellular expression of E6 and E7 oncoproteins, which interfere with the cell cycle (6). E6 oncoprotein binds to E6-AP, forming a complex that selectively binds to p53 and leads to its ubiquitin-dependent proteolytic degradation (7). The present study demonstrated that E6 immunohistochemistry was a fast and simple method for the detection of the HPV-associated oncoprotein E6 in cervical cancer tissues. As a routine practice, E6 and E7 are detected using either in situ hybridisation (11) or polymerase chain reaction (27) methodology due to the non-specific immunohistochemical staining results of antibodies used in former studies (28).

In the present study a well-tested antibody, and specific antigen retrieval and staining protocol was used, resulting in the establishment of a useful immunohistochemical evaluation protocol for the detection of the HPV E6 oncoprotein. The optimal results were obtained with the E6 antibody supplied
Table V. Cox regression of overall survival on cervical cancer variables.

\begin{tabular}{lcccc}
\hline & & & \multicolumn{2}{c}{$95.0 \%$ CI } \\
\cline { 4 - 5 } Parameters & P-value & $\begin{array}{c}\text { Hazard } \\
\text { ratio }\end{array}$ & Lower & Upper \\
\hline Age (years) & 0.071 & 1.029 & 0.997 & 1.062 \\
Histology & 0.002 & 3.576 & 1.586 & 8.063 \\
pT & 0.011 & 1.270 & 1.057 & 1.525 \\
pN & 0.045 & 2.113 & 1.016 & 4.395 \\
pM & 0.702 & 1.305 & 0.335 & 5.085 \\
Tumour grade & 0.065 & 1.717 & 0.968 & 3.048 \\
FIGO & 0.875 & 0.994 & 0.926 & 1.068 \\
E6CytIRS & 0.475 & 0.961 & 0.863 & 1.071 \\
p16CytIRS & 0.696 & 1.026 & 0.903 & 1.165 \\
p53IRS & 0.267 & 0.892 & 0.729 & 1.092 \\
p53mutIRS & 0.975 & 0.996 & 0.765 & 1.296 \\
MDM2IRS & 0.460 & 1.050 & 0.922 & 1.196 \\
Gal-3 IRS score & 0.452 & 0.937 & 0.792 & 1.109 \\
\hline
\end{tabular}

CI, confidence interval; pT, pathological tumour stage; $\mathrm{pN}$, pathological node stage; pM, pathological metastasis stage; FIGO, International Federation of Gynecology and Obstetrics stage; IRS, immunoreactive score; Cyt, cytoplasmic; mut, mutated; MDM2, MDM2 proto-oncogene; Gal-3, galectin-3.

by Abcam (Cambridge, UK). The advantage of immunohistochemical evaluation is that it is easier to apply and less expensive compared with mRNA in situ hybridisation. mRNA in situ hybridisation may be the optimal way to detect HPV; however, this method is more complicated for routine detection compared with immunohistochemistry (26). Evaluation of E6 immunohistochemical staining in cervical cancer tissue has previously revealed positive correlations with advanced T staging and FIGO classification (22). Although specific studies have indicated correlations between E6/E7 gene expression and the clinicopathological parameters of cervical cancer (26), such a correlation was not demonstrated in the present study.

An additional finding of the present study is the negative correlation between E6 and mutated p53 expression. Mutations of the gene encoding p53 (TP53) are the most frequent alterations in multiple human malignancies (29-31). In total, $>50 \%$ of human tumours contain a mutation/deletion of TP53, ranging from 5-80\% depending on the type, stage and etiology of the tumours (32). A number of previous studies have investigated a potential genetic link between these variations and cancer susceptibility, but the results have been controversial. A previous meta-analysis study from 49 pooled studies failed to demonstrate a link between a common TP53 mutation (25) and cervical cancer susceptibility (33). Later on, the same mutation was revealed to be associated with higher pancreatic cancer risk among males; however, results also indicated that it may protect Arab women against the development of breast cancer $(34,35)$. Multiple other mutations of TP53 have since been described. Mutations that deactivate p53 in cancer are primarily located in the central DNA binding domain. These mutations typically ablate the ability of the protein to bind to 
its target DNA sequences, prevent the transcriptional activation of p53 target genes. In total, $280 \%$ of the most common p53 mutants demonstrate the capacity to exert dominant-negative effects over wild-type p53 and thus prevent the activation of transcription. In contrast, only $45 \%$ of the less frequent mutants studied have this capacity (36).

The mutation detected by the antibody used in the present study is an mutation at position 20 (serine to aspartic acid), which abolishes the phosphorylation site on p53. The phosphorylation of this serine when DNA damage is detected weakens the interaction between p53 and MDM2, thereby stabilising p53 (37-39). Thus, this mutation maintains increased protein levels of p53 following DNA damage. The analysis of the immunohistochemical detection of mutated p53 revealed that cervical cancer specimens derived from squamous epithelial tissue demonstrated significantly higher expression levels compared with adenocarcinoma tissue. In addition, a positive correlation between the expression of mutated p53 and MDM2, and a negative correlation between the expression of mutated p53 and E6, were identified. Therefore, it is possible to speculate that E6 also degrades the mutated form of p53. In a previously published study, this mutation was demonstrated to be associated with the improved survival of patients with cervical cancer (25).

Finally, a positive correlation between MDM2 and gal-3 expression was demonstrated in cervical cancer tissue. Little information concerning the involvement of galectins in cervical cancer exists at present. Research has primarily focused on gal-1 $(40,41)$, gal-7 $(42,43)$ and gal-9 $(44)$. A previous publication described the influence of gal-3 on vascular endothelial growth factor $\mathrm{C}$ expression and its influence on the enhancement of cervical cancer cell invasiveness (5). The present study demonstrated that gal-3 was a negative independent prognosticator for the overall survival of patients with p16-negative cervical cancer. In this group of patients, gal-3 may be responsible for the aggressiveness of cervical cancer, whereas in p16-positive carcinomas different factors/signal transduction pathways may be responsible.

In the present study, a total of 250 cervical cancer cases were systematically analysed for the expression and interaction of E6, p53, p16, MDM2 and gal-3 in FFPE tumour tissue. Significantly increased levels of E6 staining were correlated with an advanced T stage and FIGO classification. Furthermore, MDM2 and gal-3 expression levels were positively correlated in cervical cancer. In addition, gal-3 expression levels were negatively correlated with prognosis in p16-negative cases. As gal-3 is overexpressed in the cervical cancer tissue of patients with a worse prognosis, the investigation of gal-3 inhibiting compounds is an additional task for the development of alternative treatments for this tumour type. In addition, a negative correlation between E6 and a mutated form of p53 in cervical cancer was identified. In conclusion, the results of the present study indicate that immunohistochemical staining may be a useful method for the detection the HPV E6 oncoprotein.

\section{Acknowledgements}

The present study was supported by the German Research Foundation. The authors would like to thank Professor Jutta Engel and Mr. Max Wiedemann (The Munich Cancer
Registry, Munich Tumour Centre, Munich, Germany) for providing the follow-up data.

\section{References}

1. Munoz N, Bosch FX, Castellsagué X, Díaz M, de Sanjose S, Hammouda D, Shah KV and Meijer CJ: Against which human papillomavirus types shall we vaccinate and screen? The international perspective. Int J Cancer 111: 278-285, 2004.

2. Schiffman M, Castle PE, Jeronimo J, Rodriguez AC and Wacholder S: Human papillomavirus and cervical cancer. Lancet 370: 890-907, 2007.

3. Wittekindt C, Wagner S, Mayer CS and Klussmann JP: Basics of tumor development and importance of human papilloma virus (HPV) for head and neck cancer. Laryngorhinootologie 91 (Suppl 1): S1-S26, 2012 (In German).

4. Muñoz N, Bosch FX, de Sanjosé S, Herrero R, Castellsagué X, Shah KV, Snijders PJ and Meijer CJ; International Agency for Research on Cancer Multicenter Cervical Cancer Study Group: Epidemiologic classification of human papillomavirus types associated with cervical cancer. N Engl J Med 348: 518-527, 2003.

5. Zengel P, Assmann G, Mollenhauer M, Jung A, Sotlar K, Kirchner T and Ihrler S: Cancer of unknown primary originating from oropharyngeal carcinomas are strongly correlated to HPV positivity. Virchows Archiv 461: 283-290, 2012.

6. Gupta S, Takhar PP, Degenkolbe R, Koh CH, Zimmermann H, Yang CM, Guan Sim K, Hsu SI and Bernard HU: The human papillomavirus type 11 and 16 E6 proteins modulate the cell-cycle regulator and transcription cofactor TRIP-Br1. Virology 317: 155-164, 2003.

7. Scheffner M, Huibregtse JM, Vierstra RD and Howley PM: The HPV-16 E6 and E6-AP complex functions as a ubiquitin-protein ligase in the ubiquitination of p53. Cell 75: 495-505, 1993.

8. Tang D, Wu D, Hirao A, Lahti JM, Liu L, Mazza B, Kidd VJ, Mak TW and Ingram AJ: ERK activation mediates cell cycle arrest and apoptosis after DNA damage independently of p53. J Biol Chem 277: 12710-12717, 2002.

9. Mao C, Balasubramanian A, Yu M, Kiviat N, Ridder R, Reichert A, Herkert $M$, von Knebel Doeberitz $M$ and Koutsky LA: Evaluation of a new p16(INK4A) ELISA test and a high-risk HPV DNA test for cervical cancer screening: Results from proof-of-concept study. Int J Cancer 120: 2435-2438, 2007.

10. Melkane AE, Mirghani H, Aupérin A, Saulnier P, Lacroix L, Vielh P, Casiraghi O, Griscelli F and Temam S: HPV-related oropharyngeal squamous cell carcinomas: A comparison between three diagnostic approaches. Am J Otolaryngol 35: 25-32, 2014.

11. Assmann G and Sotlar K: HPV-associated squamous cell carcinogenesis. Pathologe 32: 391-398, 2011 (In German).

12. Adams AK, Wise-Draper TM and Wells SI: Human papillomavirus induced transformation in cervical and head and neck cancers. Cancers (Basel) 6: 1793-1820, 2014.

13. Barondes SH, Castronovo V, Cooper DN, Cummings RD, Drickamer K, Feizi T, Gitt MA, Hirabayashi J, Hughes C, Kasai K, et al: Galectins: A family of animal beta-galactoside-binding lectins. Cell 76: 597-598, 1994.

14. Hirabayashi J and Kasai KI: Evolution of animal lectins. Prog Mol Subcell Biol 19: 45-88, 1998.

15. Barondes SH, Cooper DN, Gitt MA and Leffler H: Galectins. Structure and function of a large family of animal lectins. J Biol Chem 269: 20807-20810, 1994.

16. Kasai K and Hirabayashi J: Galectins: A family of animal lectins that decipher glycocodes. J Biochem 119: 1-8, 1996.

17. Hirabayashi J, Hashidate T, Arata Y, Nishi N, Nakamura T, Hirashima M, Urashima T, Oka T, Futai M, Muller WE, et al: Oligosaccharide specificity of galectins: A search by frontal affinity chromatography. Biochim Biophys Acta 1572: 232-254, 2002.

18. Boonlikit $\mathrm{S}$ and Srisantiroj $\mathrm{N}$ : Is there any clinical advantage in separating CIN 2 from CIN 3 in the current two-tiered cytological classification? Asian Pac J Cancer Prev 10: 115-118, 2009.

19. Remmele W, Hildebrand U, Hienz HA, Klein PJ, Vierbuchen M, Behnken LJ, Heicke B and Scheidt E: Comparative histological, histochemical, immunohistochemical and biochemical studies on oestrogen receptors, lectin receptors, and Barr bodies in human breast cancer. Virchows Arch A Pathol Anat Histopathol 409: 127-147, 1986. 
20. Mylonas I, Speer R, Makovitzky J, Richter DU, Briese V, Jeschke $U$ and Friese $\mathrm{K}$ : Immunohistochemical analysis of steroid receptors and glycodelin A (PP14) in isolated glandular epithelial cells of normal human endometrium. Histochem Cell Biol 114: 405-411, 2000.

21. Mylonas I, Makovitzky J, Richter DU, Jeschke U, Briese V and Friese K: Cathepsin D expression in normal, hyperplastic and malignant endometrial tissue: An immunohistochemical analysis. Acta Histochem 105: 245-252, 2003.

22. Kraljevic Z, Visković K, Ledinsky M, Zadravec D, Grbavac I, Bilandzija M, Soljacić-Vranes H, Kuna K, Klasnić K and Krolo I: Primary uterine cervical cancer: Correlation of preoperative magnetic resonance imaging and clinical staging (FIGO) with histopathology findings. Coll Antropol 37: 561-568, 2013.

23. Ozsarlak O, Tjalma W, Schepens E, Corthouts B, Op de Beeck B, Van Marck E, Parizel PM and De Schepper AM: The correlation of preoperative CT, MR imaging, and clinical staging (FIGO) with histopathology findings in primary cervical carcinoma. Eur Radiol 13: 2338-2345, 2003.

24. Horn LC, Schierle K, Schmidt D, Ulrich U, Liebmann A and Wittekind C: Current TNM/FIGO classification for cervical and endometrial cancer as well as malignant mixed mullerian tumors. Facts and background. Pathologe 32: 239-243, 2011 (In German).

25. Freier CP, Stiasny A, Kuhn C, Mayr D, Alexiou C, Janko C, Wiest I, Jeschke U and Kost B: Immunohistochemical evaluation of the role of p53 mutation in cervical cancer: Ser-20 p53-Mutant correlates with better prognosis. Anticancer Res 36: 3131-3137, 2016.

26. zur Hausen H: Papillomaviruses causing cancer: Evasion from host-cell control in early events in carcinogenesis. J Natl Cancer Inst 92: 690-698, 2000.

27. Hafner N, Gajda M, Altgassen C, Hertel H, Greinke C, Hillemanns P, Schneider A and Dürst M: HPV16-E6 mRNA is superior to cytokeratin $19 \mathrm{mRNA}$ as a molecular marker for the detection of disseminated tumour cells in sentinel lymph nodes of patients with cervical cancer by quantitative reverse-transcription PCR. Int J Cancer 120: 1842-1846, 2007.

28. Hoffmann M, Tribius S, Quabius ES, Henry H, Pfannenschmidt S, Burkhardt C, Görögh T, Halec G, Hoffmann AS, Kahn T, et al: HPV DNA, E6*I-mRNA expression and p16INK4A immunohistochemistry in head and neck cancer-how valid is p16INK4A as surrogate marker? Cancer Lett 323: 88-96, 2012.

29. Nigro JM, Baker SJ, Preisinger AC, Jessup JM, Hostetter R, Cleary K, Bigner SH, Davidson N, Baylin S, Devilee P, et al: Mutations in the p53 gene occur in diverse human tumour types. Nature 342: 705-708, 1989

30. Petitjean A, Achatz MI, Borresen-Dale AL, Hainaut P and Olivier M: TP53 mutations in human cancers: Functional selection and impact on cancer prognosis and outcomes. Oncogene 26: 2157-2165, 2007.

31. Vogelstein B, Lane D and Levine AJ: Surfing the p53 network. Nature 408: 307-310, 2000
32. Hainaut P and Hollstein M: p53 and human cancer: The first ten thousand mutations. Adv Cancer Res 77: 81-137, 2000.

33. Klug SJ, Ressing M, Koenig J, Abba MC, Agorastos T, Brenna SM, Ciotti M, Das BR, Del Mistro A, Dybikowska A, et al: TP53 codon 72 polymorphism and cervical cancer: A pooled analysis of individual data from 49 studies. Lancet Oncol 10: 772-784, 2009.

34. Sonoyama T, Sakai A, Mita Y, Yasuda Y, Kawamoto H, Yagi T, Yoshioka M, Mimura T, Nakachi K, Ouchida M, et al: TP53 codon 72 polymorphism is associated with pancreatic cancer risk in males, smokers and drinkers. Mol Med Rep 4: 489-495, 2011.

35. Alawadi S, Ghabreau L, Alsaleh M, Abdulaziz Z, Rafeek M, Akil N and Alkhalaf M: P53 gene polymorphisms and breast cancer risk in Arab women. Med Oncol 28: 709-715, 2011

36. Petitjean A, Mathe E, Kato S, Ishioka C, Tavtigian SV, Hainaut $P$ and Olivier M: Impact of mutant p53 functional properties on TP53 mutation patterns and tumor phenotype: Lessons from recent developments in the IARC TP53 database. Hum Mutat 28: 622-629, 2007.

37. Bode AM and Dong Z: Post-translational modification of p53 in tumorigenesis. Nat Rev Cancer 4: 793-805, 2004.

38. Chehab NH, Malikzay A, Stavridi ES and Halazonetis TD: Phosphorylation of Ser-20 mediates stabilization of human p53 in response to DNA damage. Proc Natl Acad Sci USA 96: 13777-13782, 1999.

39. Wade M, Wong ET, Tang M, Stommel JM and Wahl GM: Hdmx modulates the outcome of p53 activation in human tumor cells. J Biol Chem 281: 33036-33044, 2006.

40. Kim HJ, Do IG, Jeon HK, Cho YJ, Park YA, Choi JJ, Sung CO, Lee YY, Choi CH, Kim TJ, et al: Galectin 1 expression is associated with tumor invasion and metastasis in stage IB to IIA cervical cancer. Hum Pathol 44: 62-68, 2013.

41. Huang EY, Chen YF, Chen YM, Lin IH, Wang CC, Su WH, Chuang PC and Yang KD: A novel radioresistant mechanism of galectin-1 mediated by $\mathrm{H}$-Ras-dependent pathways in cervical cancer cells. Cell Death Dis 3: e251, 2012.

42. Matsui Y, Ueda S, Watanabe J, Kuwabara I, Ogawa O and Nishiyama H: Sensitizing effect of galectin-7 in urothelial cancer to cisplatin through the accumulation of intracellular reactive oxygen species. Cancer Res 67: 1212-1220, 2007.

43. Tsai CJ, Sulman EP, Eifel PJ, Jhingran A, Allen PK, Deavers MT and Klopp AH: Galectin-7 levels predict radiation response in squamous cell carcinoma of the cervix. Gynecol Oncol 131: 645-649, 2013.

44. Liang MY, Lu YM, Zhang Y and Zhang SL: Serum galectin-9 in cervical cancer. Zhonghua Yi Xue Za Zhi 88: 2783-2785, 2008 (In Chinese) 